\title{
Conhecimento e uso de plantas em uma comunidade caiçara do litoral sul do Estado do Rio de Janeiro, Brasil ${ }^{1}$
}

\author{
Rodrigo Borges ${ }^{2,3}$ e Ariane Luna Peixoto ${ }^{2}$
}

Recebido em 10/06/2008. Aceito em 26/11/2008

RESUMO - (Conhecimento e uso de plantas em uma comunidade caiçara do litoral sul do Estado do Rio de Janeiro, Brasil). A Área de Proteção Ambiental de Cairuçu (APA) localiza-se no município de Paraty, RJ. É uma unidade de conservação de uso sustentável e dispõe-se a proteger o ambiente natural e as comunidades caiçaras da região. O objetivo deste estudo foi realizar um inventário etnobotânico das plantas conhecidas e utilizadas pela comunidade caiçara que habita a praia de Martim de Sá. Moram no local 30 pessoas das quais 10 foram entrevistadas. As informações etnobotânicas foram obtidas através da observação participante e entrevistas semi-estruturadas. O material botânico coletado foi depositado no Herbário do Instituto de Pesquisas Jardim Botânico do Rio de Janeiro (RB). Foram identificadas 76 espécies pertencentes a 59 gêneros e 30 famílias botânicas consideradas úteis pelos caiçaras. As três espécies mais citadas foram: Sloanea obtusifolia (Sapopema), Scherolobium denudatum (Ingá-ferro) e Balizia pedicelaris (Timbuíba). Utilizou-se o Índice de Shannon $\left(H^{\prime}=1,81-\right.$ base 10) para a análise da diversidade de espécies. O registro sobre o uso dos recursos vegetais na comunidade estudada fornece informações que podem ser utilizadas para programas de conservação baseados no conhecimento local do ambiente.

Palavras-chave: conhecimento Caiçara, conservação da natureza, etnobotânica, floresta Atlântica, plantas úteis

ASTRACT - (Knowledge and use of plants in a Caiçara community located on the southern coast of Rio de Janeiro State, Brazil). The Cairuçu Environmental Protection Area (APA) was created to help assure the protection of the natural environment and its sustainable use by the caiçara communities in the region. This work presents an ethnobotanical inventory of the plants known and used by the caiçara community living on Martim de Sá beach in Paraty municipality, RJ. Thirty people live in the locality and ten of them were interviewed. Ethnobotanical information was obtained through participatory observations and semi-structured interviews with the local residents. All botanical material collected was deposited in the herbarium of the Instituto de Pesquisas Jardim Botânico do Rio de Janeiro (RB). A total of 76 species belonging to 59 genera and 30 botanical families that are considered useful by the caiçaras were identified. The three species most cited were Sloanea obtusifolia ("sapopema"), Scherolobium denudatum ("ingá-ferro"), and Balizia pedicelaris ("timbuíba"). The Shannon Index was used to analyze species diversity $\left(\mathrm{H}^{\prime}=1.81\right)$ and indicated that the caiçaras have a very intimate knowledge of local biodiversity when compared to studies carried out in other localities along the southeastern Brazilian coast having similar floristic composition. The inventory of the plant resources used by this community and their knowledge of the local natural environment will be useful in future conservation programs in the region.

Key words: Atlantic Forest, caiçara knowledge, ethnobotany, nature conservation, useful plants

\section{Introdução}

Os estudos de etnobotânica em geral incluem levantamentos de espécies e têm contribuído para planos de conservação e manejo de ecossistemas (Prance 1995). É senso comum na literatura conservacionista que os povos indígenas e comunidades tradicionais têm conhecimento dos usos para quase todas as plantas das florestas onde habitam e que esse é um caminho para entender quão proveitosa pode ser a conservação das florestas tropicais (Prance 1991). Diegues \& Arruda (2001) salientam a importância da contribuição que os estudos em etnobotânica têm trazido na medida em que buscam descobrir a lógica subjacente ao conhecimento humano do mundo natural, as taxonomias e as classificações totalizadoras. Para esses autores, conhecimento tradicional pode ser definido como "o saber e o saber-fazer a respeito do mundo natural e sobrenatural gerados no âmbito da sociedade não-urbana/ industrial e transmitido oralmente de geração a geração".

O território brasileiro apresenta uma das maiores diversidades biológicas e culturais do planeta. Conta com mais de 500 áreas indígenas reconhecidas pelo Estado, além de diversos grupos de populações rurais não-indígenas espalhadas pelo litoral e pelo interior, incluindo caiçaras, ribeirinhos, caboclos, quilombolas, agricultores migrantes, entre outros (Diegues \& Arruda 2001).

O termo caiçara tem origem no vocábulo tupi-guarani caá-içara (Adams 2000), primeiramente utilizado para designar as estacas colocadas em torno das tabas ou aldeias e o cerco feito com galhos de árvores fincados no chão para cercar o peixe dentro da água. Com o passar dos anos passou a ser o nome dado às palhoças construídas nas praias para abrigar canoas e utensílios dos pescadores e, mais recentemente, para identificar os indivíduos e/ou comunidades das áreas costeiras dos atuais Estados do Rio de Janeiro, São Paulo, Paraná e norte de Santa Catarina. Estas comunidades têm modo de vida baseado no extrativismo vegetal, na agricultura itinerante, pesca e no artesanato (Diegues \& Arruda 2001).

A literatura sobre comunidades caiçaras é extensa. Adams (2000) levantou 180 publicações sobre comunidades caiçaras desde 1943 até 2000, sendo que 35\% desses estudos foram publicados na década de 1990. Diegues \& Arruda (2001) mostram, em seu levantamento de referências bibliográficas sobre os caiçaras, que o extrativismo é a atividade mais realizada por essas comunidades sendo assinalado em $63 \%$

\footnotetext{
1 Parte da Dissertação de Mestrado do primeiro Autor

2 Instituto de Pesquisas Jardim Botânico do Rio de Janeiro, Rio de Janeiro, RJ, Brasil

3 Autor para correspondência: r.borges78@gmail.com
} 
do total de 104 trabalhos publicados. O extrativismo caiçara é feito no mar e estuários, onde ocorre a pesca e a coleta de crustáceos e moluscos, e nas restingas e matas onde um grande número de espécies de plantas é utilizado para finalidades domésticas e comerciais. Entre os trabalhos citados apenas 15\% deles foram desenvolvidos no Estado do Rio de Janeiro (Diegues 2003).

A comunidade caiçara de Martim de Sá, na qual se realizou a presente pesquisa foi estudada anteriormente por duas pesquisadoras: Sinay (2002) buscou compreender o processo de adaptação da comunidade ao ecoturismo e compreender a identidade cultural da comunidade como bem patrimonial e como elemento de risco no planejamento dessa atividade. A comunidade de Martim de Sá foi escolhida por residir em um local onde atividades de ecoturismo estavam se iniciando. Esse fato permitiu à autora refletir sobre as conseqüências de tal atividade e ela informa que, apesar de Martim de Sá estar inserida nos limites de duas Unidades de Conservação (UC), está sobre forte ameaça de degradação ambiental devido à especulação imobiliária incentivada pelo crescimento do fluxo turístico sem planejamento e facilitado pela falta de fiscalização dos órgãos ambientais responsáveis por essas áreas.

Cavalieri (2003) estudou o processo de reclassificação da Reserva Ecológica da Juatinga (RE da Juatinga) prevista pela lei que instituiu o Sistema Nacional de Unidades de Conservação (SNUC 2000). Segundo a autora, as comunidades da RE da Juatinga vivenciaram, da década de 1950 até a década de 1980, uma forte especulação imobiliária e a chegada de grileiros. A partir da década de 1990, somados aos problemas fundiários surgiram conflitos ambientais devido à criação desta UC de natureza non edificandi. $\mathrm{Na}$ regulamentação da UC, ficaram preservadas as áreas tradicionalmente ocupadas pelas comunidades caiçaras, mas a sua perpetuidade ainda não foi discutida. Atualmente, além dos desdobramentos da chegada dos grileiros, dos turistas e da criação da UC, os moradores enfrentam o desafio de continuar em suas moradias devido a reclassificação da RE da Juatinga.

O conhecimento tradicional pode fornecer informações muito úteis no planejamento participativo de unidades de conservação com sustentabilidade (Hanazaki 2002). Alguns autores argumentam que o conhecimento tradicional pode complementar o conhecimento científico ao fornecer experiências práticas pela vivência nos ecossistemas e, por conseguinte, responder a mudanças nestes ecossistemas (Berkes et al. 1998; Hanazaki 2002). Considerando que a comunidade caiçara de Martim de Sá habita uma UC de uso sustentável e apresenta conflito na questão da posse de terra; vive numa região apontada como de alta diversidade biológica; encontra-se afastada de um centro urbano, cujo deslocamento até ele é dificultado por longas caminhadas ou uso de barcos, o estudo proposto partiu da hipótese de encontrar na comunidade um elevado conhecimento sobre as plantas locais. Buscou-se responder às seguintes questões: Quais plantas são conhecidas e utilizadas pela comunidade? Como o conhecimento tradicional está distribuído entre os moradores em relação à idade e gênero? Qual é a categoria de manejo mais adequada para a região onde vive a comunidade?

\section{Material e métodos}

Área de estudo - O território do Estado do Rio de Janeiro ocupa uma área de $43.650 \mathrm{~km}^{2}$. Estima-se que à época do descobrimento, a Mata Atlântica cobria cerca de $98 \%$ desse território (Instituto Estadual de Florestas 2006). Segundo a mesma fonte, estudo da Comissão para o Tombamento do Sistema Serra do Mar/Mata Atlântica em 1990 estimou a cobertura florestal em $6.907 \mathrm{~km}^{2}$, ou seja, 15,95\% da área do Estado. A Mata Atlântica é um dos ecossistemas mais diversos e ameaçados no mundo, apontado como o quarto hotspot mais importante para a conservação em termos de biodiversidade (Myers et al. 2000).

A Praia de Martim de Sá localiza-se na região da Área de Proteção Ambiental (APA) de Cairuçu, inserida nos limites da Reserva Ecológica (RE) da Juatinga, no município de Paraty, litoral sul do estado do Rio de Janeiro (Fig. 1). São duas UC que se sobrepõem em parte dos seus limites e que apresentam diferentes objetivos de conservação da natureza. A APA de Cairuçu (2322'04'"- $23^{\circ} 13$ '30's

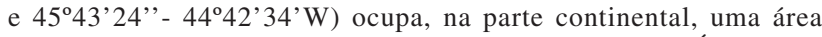
de 33,800 ha, além de uma parte insular com 63 ilhas. É uma UC Federal de uso sustentável criada pelo Decreto No 89.242 de 27 de dezembro de 1983, gerenciada pelo IBAMA, e tem como principal objetivo assegurar a proteção do ambiente natural, que abriga espécies raras e ameaçadas de extinção, paisagens de grande beleza cênica, sistemas hidrológicos e as comunidades caiçaras integradas nesse ecossistema.

A RE da Juatinga é uma UC Estadual, criada pelo Decreto Estadual $\mathrm{N}^{\text {o }} 17.981$, de 30 de outubro de 1992, e tem como objetivo preservar o ecossistema local, composto por costões rochosos, remanescentes florestais de Mata Atlântica, restingas e mangues que, em conjunto com o mar, ao fundo, forma cenário de notável beleza, apresentando peculiaridades não encontradas em outras regiões do Estado, "além de fomentar a cultura caiçara local, compatibilizando a utilização dos recursos naturais com os preceitos conservacionistas estabelecidos neste Decreto através do desenvolvimento de programa de Educação Ambiental específico através da Fundação Instituto Estadual de Florestas."

Abrange uma área de 8.000 ha e abriga 12 núcleos de ocupação de comunidades caiçaras nas seguintes localidades: Saco do Mamanguá, Praia Grande da Cajaíba, Martim de Sá, Itaoca, Calhaus, Pouso, Juatinga, Cairuçu das Pedras, Ponta Negra, Sono, Antigos e Antiguinhos. Os moradores são, em sua maioria, aparentados e distribuem-se em trechos delimitados ao longo do litoral. Vivem de pesca artesanal, agricultura de subsistência e mais recentemente do turismo que vem sendo o causador de um processo de descaracterização cultural (Garrote 2004). Os núcleos relacionam-se entre si e usam a cidade de Paraty como centro de comércio e serviços, apesar da precariedade de acesso, que é feito a pé por trilhas ou barcos. O Instituto Estadual de Floresta (IEF) é o órgão responsável pela gestão da RE da Juatinga.

De acordo com a carta geológica do estado do Rio de Janeiro (CPRM 1983) predominam na região solos do tipo podzólico com suas variantes nas áreas de maiores altitudes e encostas, sendo mais observado o tipo latossolo amarelo-litossol. Na faixa litorânea predominam os solos hidromórficos. O clima da região é superúmido, Af na Classificação de Köppen, com pouco ou nenhum déficit de água, mesotérmico, com temperaturas médias anuais em torno de $26^{\circ} \mathrm{C}$ e $27^{\circ} \mathrm{C}$. Não há período seco definido e a umidade relativa do ar permanece em torno de $80 \%$ durante o ano todo (FIDERJ 1978).

A vegetação predominante pertence ao domínio da Floresta Ombrófila Densa (Veloso et al. 1991), ocorrendo também os subtipos vegetacionais floresta de restinga e manguezais. A floresta chega, em 


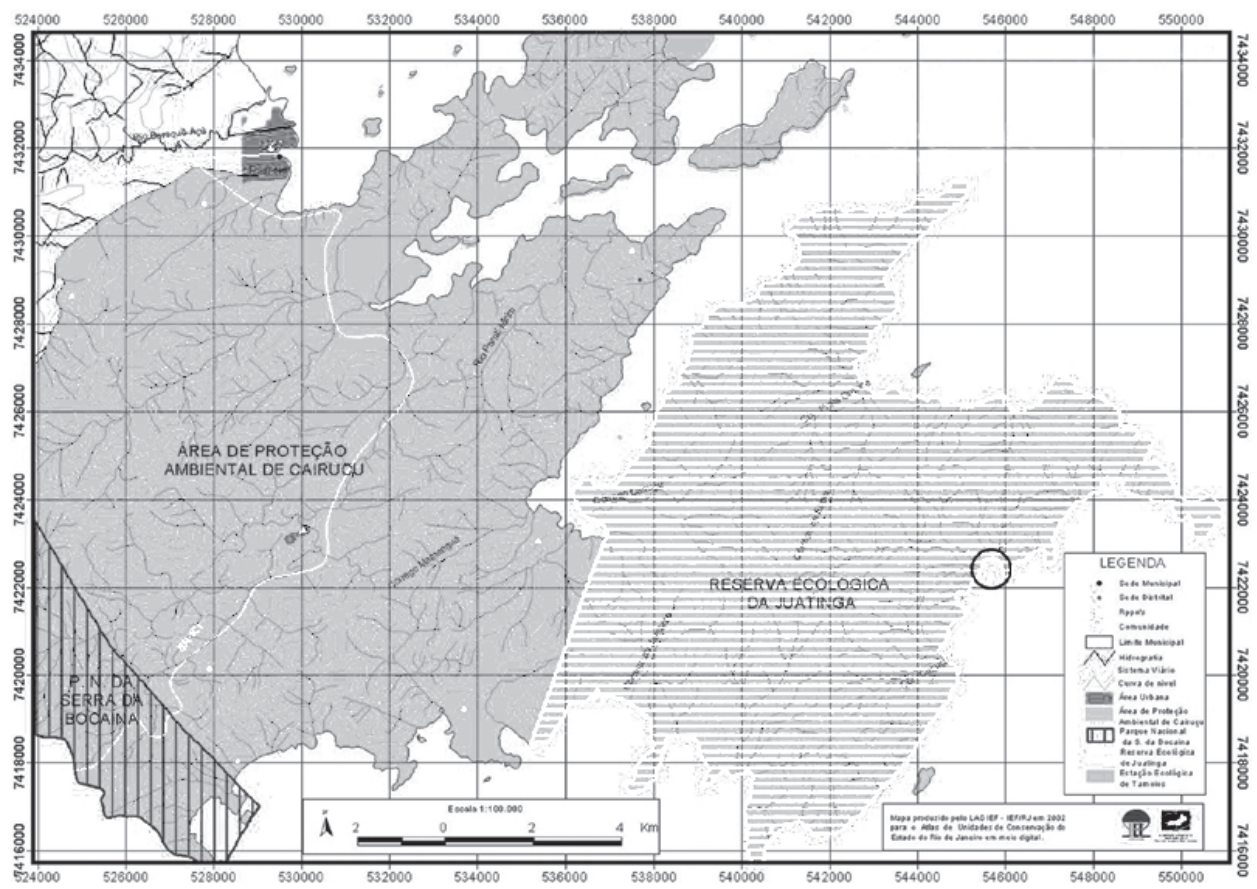

Figura 1. Mapa do município de Paraty, RJ, ressaltando as Unidades de Conservação locais: o Parque Nacional da Serra da Bocaina, a Área de Proteção Ambiental de Cairuçu e a Reserva Ecológica da Juatinga. O círculo preto destaca a praia de Martim de Sá. (Fonte: Adaptado do Atlas das Unidades de Conservação da Natureza, Governo do Estado do Rio de Janeiro/SEMA, 2001).

vários pontos, até próximo à estreita faixa arenosa da praia, ou a linha da costa, na parte rochosa. Por toda região encontra-se também vegetação antropicamente alterada em diferentes estágios sucessionais como campos de ocupação agropecuária, capoeiras e vegetação secundária (Marques et al. 1997).

A região onde se localiza a comunidade Martim de Sá possui relevo bastante acidentado e é circundada por montanhas. O litoral é rochoso e favorece a chegada da floresta até o limite com o mar. A praia de Martim de Sá, com cerca de 500 metros de comprimento, é precedida por um trecho de restinga. Entre a restinga e a cadeia montanhosa há uma área plana onde se encontram quatro residências próximas umas das outras. O espaço entre elas é mantido limpo pelos moradores. Caminhando aproximadamente meia hora no sentido SW encontram-se quatro outras residências, no local denominado pelos moradores de Saco das Anchovas. Essas casas são construídas em uma encosta íngreme. Ambos os grupos de casas ficam contornados por vegetação arbórea, e têm, junto a eles, uma casa de farinha (Fig. 2). No Saco das Anchovas os moradores mantêm um porto para atracar os barcos e canoas. Segundo os moradores, Saco das Anchovas pertence a Martim de Sá.

A comunidade caiçara de Martim de Sá - Antes de iniciar-se a pesquisa de campo conversou-se com o diretor da APA de Cairuçu - IBAMA em Paraty, a respeito da pesquisa, então planejada. O diretor, nessa conversa, apontou em um mapa da APA de Cairuçu as comunidades que viviam mais isoladas em trechos bem preservados de floresta. Optou-se pela comunidade de Martim de Sá já que se encontra bem afastada do principal centro urbano (cerca de $30 \mathrm{~km}$ da cidade de Paraty) e em uma região apontada como de alta diversidade biológica (Marques 1997).

Após essa etapa fez-se uma visita à comunidade para explicitar as intenções da pesquisa a ser realizada. Para a chegada até a comunidade partiu-se do cais de Paraty, utilizando como meio de transporte um barco e após duas horas, desembarcou-se na praia Pouso da Cajaíba. Dessa praia, seguiu-se caminhando em direção a Martim de Sá, por uma hora e meia, em trilha, e chegou-se à casa do líder comunitário, apontado pelo diretor da APA de Cairuçu. Depois de instalado em uma barraca de acampamento, com a permissão do líder comunitário, conversou-se com ele a respeito da possibilidade de desenvolvimento da pesquisa envolvendo a comunidade e uma área de floresta próxima as suas casas.

Nessa primeira visita foi possível reunir os moradores locais e fazer uma apresentação oral sobre a intenção da pesquisa, a metodologia a ser utilizada, a sua duração e o tempo que o pesquisador permaneceria ali em cada visita. O líder comunitário, com a concordância verbal de todos os presentes concordou em firmar, posteriormente, um documento de anuência à pesquisa.

Os moradores da Comunidade Caiçara Martim de Sá se afirmam caiçaras ou "aqueles que sabem caçar, pescar e roçar" (líder comunitário), e admitem que a denominação foi trazida pelas "pessoas de fora". A comunidade engloba 30 pessoas, entre homens, mulheres, jovens e crianças, que residem em oito casas. Não existem cercas ao redor das casas e as trilhas abertas na mata permitem o acesso a elas. As casas são construídas com a frente voltada para o mar e protegidas do vento por vegetação.

A organização social da comunidade é baseada no grupo familiar, unidade básica e vital de existência. As mulheres são mães de família, trabalhadoras do lar e da roça. O papel delas é de extrema importância para a manutenção do grupo doméstico, sua reprodução, produção e sobrevivência. São responsáveis pelo preparo dos alimentos, produção de farinha de mandioca, abastecimento de lenha, cuidado com pequenos animais de criação (patos, galinhas) e a criação dos filhos. Os homens são encarregados das atividades de pesca, derrubada e queimada da mata para o estabelecimento de roças (quando separam lenha que é, de modo geral, transportada pelas mulheres) construção das moradias, construção e condução de canoas e barcos, e manutenção da limpeza dos quintais para recepção de turistas, comumente exercida em Martim de Sá. Essas características estão, de modo geral, de acordo com as descrições de Adams (2000) para as comunidades caiçaras presentes na Mata Atlântica.

Os métodos - No período de maio/2005 a maio/2006 foram realizadas cinco viagens à Martim de Sá, cada viagem com a duração de sete dias em campo para coleta de dados e dos espécimes vegetais. Foram realizadas entrevistas semi-estruturadas com dez informantes selecionados pelo método bola de neve (Bernard 1995), sendo cinco homens e cinco mulheres, em suas residências. Como se trata de uma comunidade pequena, a aplicação deste método nos mostrou todos os 
moradores adultos. O restante da comunidade é formado por jovens e crianças, que não foram indicados por nenhum informante. Com cada informante utilizou-se um elenco básico de perguntas baseadas nos trabalhos de Camargo (2003) e Cunningham (2000), porém adaptados à realidade local. Posteriormente empregou-se a técnica "caminhando na floresta" (Alexiades 1996) com os homens, quando foram coletadas amostras botânicas e informações sobre os diferentes usos das plantas. Tal método foi aplicado em um trecho delimitado da floresta (Fig. 2), onde se realizou um inventário florístico e fitossociológico visando conhecer parte da flora local e também no trecho de floresta que liga Martim de Sá a Saco das Anchovas, local mais freqüentado pelos moradores. Os informantes foram entrevistados individualmente, como recomendado por Phillips \& Gentry (1993a), para evitar que as respostas fossem influenciadas por outro informante. As plantas citadas nas entrevistas foram coletadas na floresta, nos quintais ao redor das residências dos informantes e duas espécies na restinga limítrofe aos quintais, na Praia de Martim de Sá. Empregou-se ainda a técnica "artefato-entrevista" (Albuquerque \& Lucena 2004), na qual se coletam informações sobre o material vegetal do qual são feitos diferentes objetos encontrados na comunidade. Conhecendo-se o nome vulgar coleta-se a amostra botânica e, após confirmá-la com os informantes, busca-se a sua identificação. Esta técnica foi empregada individualmente com todos os informantes.

As amostras botânicas coletadas foram prensadas e preservadas com álcool $92,8^{\circ}$ em sacos plásticos vedados durante o período de permanência no campo (Mori et al. 1989). Após cada um dos períodos no campo, as amostras foram secas em estufa de lâmpadas incandescentes no Instituto de Pesquisas Jardim Botânico do Rio de Janeiro (JBRJ). A identificação botânica até o nível hierárquico mais excludente foi realizada utilizando-se literatura especializada e comparando-se as amostras com exsicatas do herbário do JBRJ, onde os exemplares coletados foram depositados. Os dados sobre os espécimes podem ser acessados on line pelo sítio http://www.jbrj.gov.br/ jabot. Para algumas famílias, a identificação taxonômica foi feita ou confirmada por especialistas do JBRJ e de outras instituições sediadas no Rio de Janeiro.

A grafia dos binômios científicos foi conferida em revisões taxonômicas recentes e/ou utilizando a base de dados Tropicos, versão on line, acessível pelo sítio http://www.tropicos.org. Os nomes dos autores dos táxons encontram-se abreviados segundo Brummitt \& Powel (1992). Para a listagem dos táxons seguiu-se o APG II (2003).
Neste trabalho buscou-se classificar a origem das plantas coletadas. Para tal, consideraram-se as seguintes definições: plantas nativas as pertencentes ao domínio mata atlântica e plantas exóticas os espécimes provenientes de outras áreas.

Foram calculados o Valor de Uso para Espécie (Phillips \& Gentry 1993a; b), de onde se obtém um valor de uso da espécie por cada informante (a) e, posteriormente, o valor de uso da espécie (b), e o índice de Shannon-Wiener (Magurran 1988), este último com intuito de comparar os dados dessa pesquisa com resultados oriundos de pesquisas etnobotânicas realizadas em diferentes comunidades costeiras do litoral sudeste brasileiro (Figueiredo et al. 1997; Rossato et al. 1999; Hanazaki et al. 2000; Fonserca-Kruel \& Peixoto 2004). Esse índice é baseado na idéia de que a diversidade de um sistema natural pode ser medida como informação contida em uma mensagem (Begossi 1996).

\section{Resultados e discussão}

Modo de vida e economia de subsistência - Na área onde vive a comunidade caiçara Martim de Sá não há luz elétrica nem telefonia fixa ou móvel. Não há escola e igreja. O turismo, iniciado a partir da década de 1990, impôs adaptações ao modo de vida dos moradores em épocas de feriados prolongados (Sinay 2002). Uma pequena mercearia foi aberta no ano de 2005, junto à casa do líder comunitário, para venda de utensílios e alimentos aos turistas que acampam na área. Não há recolhimento de lixo por parte da prefeitura de Paraty nem pelos órgãos gestores da área.

A agricultura de subsistência realizada pelos moradores foi desestimulada, com a criação da RE da Juatinga, mantendo-se apenas roçados de mandioca, próximos as suas casas e cultivados comunitariamente. A farinha de mandioca produzida é consumida internamente e não há comercialização. Sinay (2002) verificou que do início da década de 1990 até o carnaval de 1999 o número de turistas nas altas temporadas não era grande nessa praia, influenciado pela dificuldade de acesso ao local, que é

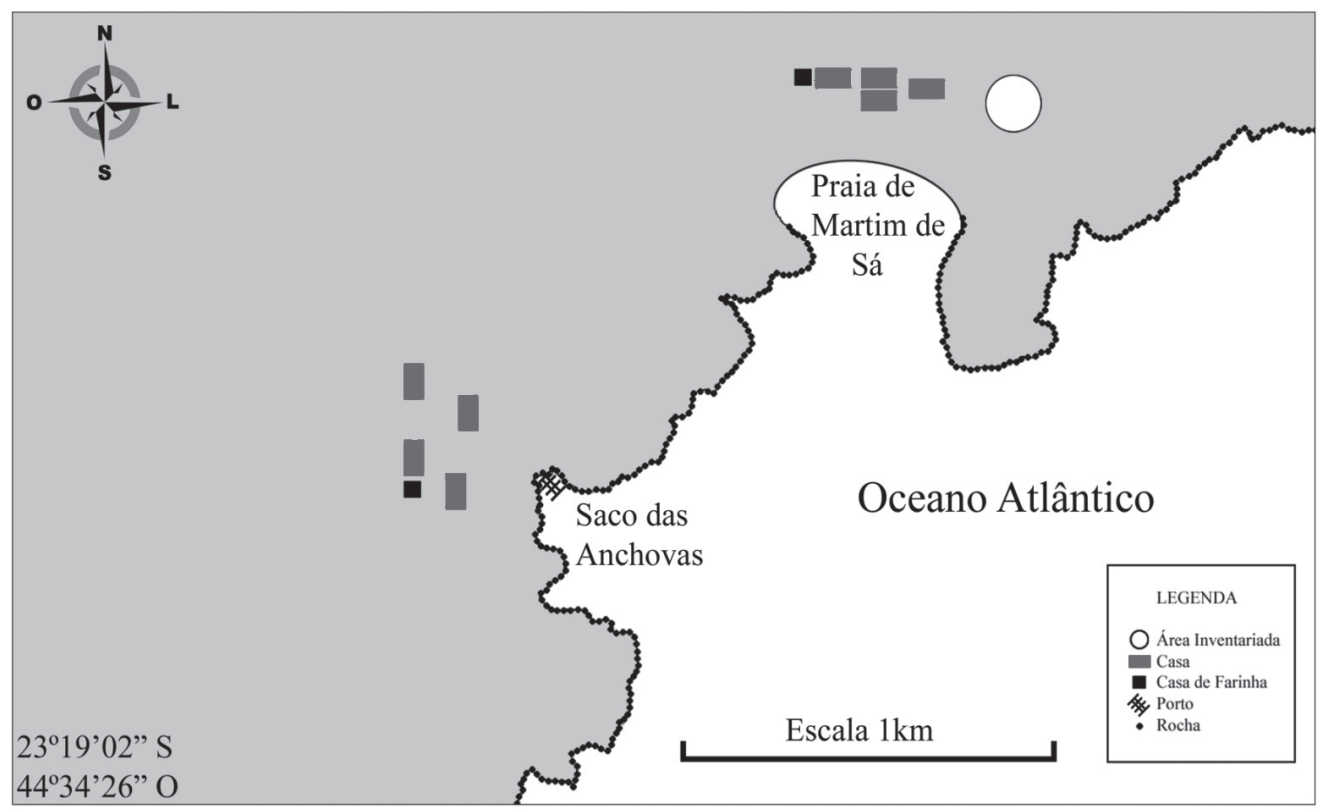

Figura 2. Croqui da Praia de Martim de Sá, Paraty, RJ, assinalando o porto na localidade de Saco das Anchovas, as casas dos moradores locais, as casas de farinha e a área onde foi efetuado o inventário florístico. 
feito por barcos saindo de Paraty e Paraty-Mirim com destino à Praia de Pouso da Cajaíba, onde começa a trilha de mais de uma hora de caminhada com destino a essa praia, ou do condomínio Laranjeiras, cujo acesso é restrito. Além da dificuldade de acesso, a autora também atribuiu o pequeno fluxo turístico ao tipo de propaganda sobre o local que é feito, predominantemente, boca-a-boca (98\% dos casos).

A partir de 2000, em feriados prolongados, houve um aumento de $200 \%$ no fluxo de turistas que procuram a praia para acampar chegando ao limite máximo de 240 barracas no carnaval de 2001 (Sinay 2002). Ao caracterizar o turista que frequienta o local, Sinay (2002) informa que a faixa etária está concentrada entre 15 e 30 anos e são, predominantemente, estudantes dos estados do Rio de Janeiro (72\%), São Paulo (17\%) e outros (11\%), com pouca renda. Entre os entrevistados, $42 \%$ são estudantes de graduação. $\mathrm{O}$ aumento do turismo na comunidade de Martim de Sá provocou mudanças no seu cotidiano, nas relações familiares, notadamente no que diz respeito aos papéis desempenhados por homens e mulheres, em sua economia e nas representações referentes à natureza (Sinay 2002).

Nas viagens de campo realizadas em janeiro e março/2006, observou-se turistas acampados em área próxima às casas dos moradores de Martim de Sá. Nesses períodos, além das suas tarefas do cotidiano, as mulheres serviram refeições a alguns turistas enquanto os homens aumentavam a quantidade de pescado para fazer parte dessas refeições. No final desse período, o lixo reciclável deixado pelos turistas foi recolhido pelos moradores da comunidade, e levado de barco para Paraty. O lixo orgânico foi separado e enterrado em local por eles definido.

Embora o turismo tenha aumentado o Saco das Anchovas não é o lugar mais procurado pelos excursionistas. Como o local tem porto e é passagem para outras localidades da RE da Juatinga, os caminhantes permanecem apenas algumas horas para conhecer o local e pedir informações referentes às trilhas existentes aos moradores (informantes desse estudo).

Os informantes e seu saber sobre as plantas - Os entrevistados tinham idades entre 21 e 63 anos. As entrevistas com os moradores mais idosos revelaram que eles têm um vasto saber sobre plantas tais como épocas de floração e frutificação, vinculação delas a um determinado típico fisionômico (restinga, floresta, roça/quintal), uso das espécies e também sobre outros fenômenos da natureza tais como direção dos ventos, marés, localização de acidentes geográficos e este saber é vivenciado na comunidade. Phillips \& Gentry (1993a) e Hanazaki et al. (2000) informam que de maneira geral os mais idosos conhecem uma diversidade maior de plantas úteis, saber que foi acumulado ao longo de suas vidas. A pesquisa realizada na comunidade Martim de Sá corrobora com essas informações.
Os moradores da comunidade caiçara de Martim de Sá usam plantas nativas e exóticas para alimentação, construção de casas e canoas, para medicamentos, ornamentação e lenha. Durante a pesquisa um total de 76 espécies foram citadas como úteis, pertencentes a 59 gêneros e 30 famílias botânicas. Foram feitas 355 citações das 76 espécies úteis. As famílias botânicas com maior número de espécies citadas como úteis foram Myrtaceae (10 espécies), Fabaceae (sete espécies), Arecaceae (cinco espécies), Lauraceae (cinco espécies), Euphorbiaceae (cinco espécies), Rutaceae (quatro espécies) e Bignoniaceae (quatro espécies). Foram indicadas pela maioria dos informantes e apresentam usos múltiplos. Fonseca-Kruel \& Peixoto (2004) também encontraram o maior número de citações pertencentes à família Myrtaceae.

Das espécies citadas que nos foram mostradas e/ou coletadas $56,4 \%$ localizam-se na floresta, $39,7 \%$ nos quintais e roças e $3 \%$ na restinga. Os nomes científicos e populares das espécies citadas, bem como as categorias de uso, os valores de uso, o local onde foram coletadas e a parte utilizada encontram-se na Tab. 1.

Categorias de uso e valor de uso das espécies citadas - Os informantes identificaram 29 usos diferentes para as espécies que foram ordenados em cinco categorias de uso distintas: alimentar, construção/tecnologia, lenha, medicinal e ornamental (Tab. 2).

A categoria de uso com o maior número de espécies foi construção/tecnologia com 41 espécies citadas pertencentes a 17 famílias botânicas (48,2 \% do total). As três espécies com valores de uso (VU) máximos foram sapopema (Sloanea obtusifolia), ingá-ferro (Sclerolobium denudatum) e timbuíba (Balizia pedicelaris) com valores entre 1,3 e 1,1. São espécies de grande valor madeireiro e procuradas para a fabricação de canoas, tábuas e esteios para construções domésticas e pesqueiras. O cedro (Cedrela fissilis) e o jequitibá (Cariniana estrellensis) também são utilizados na construção de canoas e ambos apresentaram VU de 0,7. Ainda em relação às espécies utilizadas para a construção de canoas e utensílios para a pesca, o ipê-roxo (Tabebuia heptaphylla) e o ipê-amarelo (Tabebuia serratifolia) são utilizados no desdobro de tábuas para barcos, pois, segundo os entrevistados, são madeiras que podem ficar em contato com a água. A Fig. 3 mostra as distribuições das espécies por classes de valor de uso, em porcentagem.

Para a fabricação de remos, as espécies preferidas são o guacá (Pausandra morisiana) e a caxeta (Tabebuia cassinoides), ambos com VU de 0,5. A quaresma ou tingicuia (Tibouchina sp.) é empregada para tingir e impermeabilizar redes de pesca e melhorar a resistência ao ataque dos peixes quando utilizadas. Todas as plantas dessa categoria de uso são nativas e não são cultivadas pelos moradores. Os processos de reconhecimento na mata das espécies utilizadas nesta categoria de uso está difundido entre todos os cinco homens entrevistados, independente da idade, e é 
Tabela 1. Relação das espécies vegetais utilizadas pela comunidade caiçara de Martim de Sá, Paraty, RJ, Brasil, em ordem alfabética de famílias botânicas acompanhadas pelos nomes populares, categorias de uso (cat), hábito (hab), valores de uso (VU), origem e local de coleta (O/loc) e parte utilizada (par). (al = alimentar, $\mathrm{co}=$ construção/tecnologia, le = lenha, $\mathrm{me}=$ medicinal e or $=$ ornamental, $\mathrm{ab}=$ arbusto, $\mathrm{av}=$ árvore, $\mathrm{hb}=$ herbácea e li $=$ liana, e $=$ exótica, $\mathrm{n}=$ nativa, $\mathrm{m}=$ mata, $\mathrm{q}=$ quintal e $\mathrm{r}=$ restinga, cau $=$ caule, cas $=$ casca, esp $=$ espata, fo = folhas, $\mathrm{fr}=$ fruto, ra $=$ raiz, $?=$ plantas cuja origem não pode ser determinada).

\begin{tabular}{|c|c|c|c|c|c|c|}
\hline Família/Nome científico & Nome popular & Cat & $\mathrm{Hab}$ & VU & $\mathrm{O} / \mathrm{Loc}$ & Par \\
\hline \multicolumn{7}{|l|}{ AMARANTHACEAE } \\
\hline Alternanthera brasiliana (L.) Kuntze & estomalina & me & $\mathrm{hb}$ & 0,3 & $\mathrm{e} / \mathrm{q}$ & fo \\
\hline Pfaffia paniculata (Mart.) O. Kuntze & terranicina & me & $\mathrm{hb}$ & 0,7 & $\mathrm{e} / \mathrm{q}$ & fo \\
\hline \multicolumn{7}{|l|}{ ANACARDIACEAE } \\
\hline Mangifera indica $\mathrm{L}$. & manga & al & av & 0,1 & $\mathrm{e} / \mathrm{q}$ & $\mathrm{fr}$ \\
\hline Schinus terebinthifolia Raddi & aroeira & le & av & 0,4 & $\mathrm{n} / \mathrm{q}$ & cau \\
\hline \multicolumn{7}{|l|}{ APOCYNACEAE } \\
\hline Aspidosperma polyneuron Mull. Arg. & peroba & co & av & 0,7 & $\mathrm{n} / \mathrm{m}$ & $\mathrm{cau}$ \\
\hline \multicolumn{7}{|l|}{ ARACEAE } \\
\hline Heteropsis $\mathrm{cf}$. rigidifolia Engl. & cipó-timupeba-chato & co & li & 0,2 & $\mathrm{n} / \mathrm{m}$ & $\mathrm{cau}$ \\
\hline \multicolumn{7}{|l|}{ ARECACEAE } \\
\hline Astrocaryum aculeatissimum (Schott) Burret & airí* & al & $\mathrm{ab}$ & 0,4 & $\mathrm{n} / \mathrm{m}$ & $\mathrm{cau}$ \\
\hline Attalea dubia (Mart.) Burret & indaiá* & or & $\mathrm{ab}$ & 0,2 & $\mathrm{n} / \mathrm{m}$ & esp \\
\hline Cocos nucifera $\mathrm{L}$. & côco* & al & $\mathrm{ab}$ & 0,4 & $\mathrm{e} / \mathrm{q}$ & fr \\
\hline Euterpe edulis Mart. & palmito-jussara* & al & av & 1,0 & $\mathrm{n} / \mathrm{m}$ & $\mathrm{cau}$ \\
\hline Syagrus pseudococus (Raddi) Glassman & pati* & or & av & 0,2 & $\mathrm{n} / \mathrm{m}$ & esp \\
\hline \multicolumn{7}{|l|}{ ASTERACEAE } \\
\hline Vernonia condensata Baker & boldo-folha-fina & me & $\mathrm{hb}$ & 0,6 & $\mathrm{e} / \mathrm{q}$ & fo \\
\hline \multicolumn{7}{|l|}{ BIGNONIACEAE } \\
\hline Jacaranda caroba DC. & carobinha & co & av & 0,2 & $\mathrm{n} / \mathrm{m}$ & cau \\
\hline Tabebuia cassinoides (Lam.) DC. & caxeta & co & av & 0,5 & $\mathrm{n} / \mathrm{m}$ & cau \\
\hline T. heptaphylla (Vell.) Toledo & ipê-roxo & $\mathrm{me} / \mathrm{co}$ & av & 0,8 & $\mathrm{n} / \mathrm{m}$ & cas/cau \\
\hline T. serratifolia (Vahl.) Nicholson & ipê-amarelo & co & av & 0,5 & $\mathrm{n} / \mathrm{m}$ & cau \\
\hline \multicolumn{7}{|l|}{ BROMELIACEAE } \\
\hline Ananas comosus (L.) Merr. & abacaxi* & al & $\mathrm{hb}$ & 0,4 & $\mathrm{n} / \mathrm{q}$ & $\mathrm{fr}$ \\
\hline \multicolumn{7}{|l|}{ CARICACEAE } \\
\hline Carica papaya $\mathrm{L}$. & mamão & al & $a b$ & 0,2 & $\mathrm{e} / \mathrm{q}$ & fr \\
\hline \multicolumn{7}{|l|}{ CHENOPODIACEAE } \\
\hline Chenopodium ambrosioides L. & erva-de-santa-maria & me & $\mathrm{hb}$ & 0,7 & $\mathrm{e} / \mathrm{q}$ & fo \\
\hline \multicolumn{7}{|l|}{ CHRYSOBALANACEAE } \\
\hline Licania hoehnei Pilg. & milho cozido & le & av & 0,4 & $\mathrm{n} / \mathrm{q}$ & $\mathrm{cau}$ \\
\hline \multicolumn{7}{|l|}{ CRASSULACEAE } \\
\hline Kalanchoe brasiliensis Camb. & saião & me & $\mathrm{hb}$ & 0,2 & $\mathrm{e} / \mathrm{q}$ & fo \\
\hline ELAEOCARPACEAE & & & & & & \\
\hline Sloanea monosperma Vell. & sapopema & co & av & 1,3 & $\mathrm{n} / \mathrm{m}$ & $\mathrm{cau}$ \\
\hline ERYTROXYLACEAE & & & & & & \\
\hline Erythroxylum vacciniifolium Mart. & pimentinha & le & av & 0,2 & $\mathrm{n} / \mathrm{m}$ & $\mathrm{cau}$ \\
\hline EUPHORBIACEAE & & & & & & \\
\hline Hyeronima alchorneoides Allemão & aricurana & co & av & 0,7 & $\mathrm{n} / \mathrm{m}$ & $\mathrm{cau}$ \\
\hline Jatropha sp. & nogra & co & av & 0,2 & $? / \mathrm{q}$ & $\mathrm{cau}$ \\
\hline Manihot esculenta Crantz & mandioca* & al & $\mathrm{hb}$ & 1,0 & $\mathrm{n} / \mathrm{q}$ & $\mathrm{ra}$ \\
\hline Pausandra morisiana (Casar.) Radlk. & guacá & co & av & 0,5 & $\mathrm{n} / \mathrm{m}$ & $\mathrm{cau}$ \\
\hline Pera glabrata (Schott) Poepp. ex Baill. & casca-preta & $\mathrm{co} / \mathrm{le}$ & av & 0,2 & $\mathrm{n} / \mathrm{m}$ & $\mathrm{cau}$ \\
\hline FABACEAE & & & & & & \\
\hline Balizia pedicelaris (DC.) Barneby \& Grimes & timbuíba & co & av & 1,1 & $\mathrm{n} / \mathrm{m}$ & $\mathrm{cau}$ \\
\hline Hymenaea courbaril L. & jataí & co & av & 0,3 & $\mathrm{n} / \mathrm{m}$ & $\mathrm{cau}$ \\
\hline Inga laurina (Sw.) Willd. & ingá-macaco & $\mathrm{co}$ & av & 0,6 & $\mathrm{n} / \mathrm{m}$ & cau \\
\hline I. sessilis (Vell.) Mart. & ingá-da-capoeira & al & av & 0,4 & $\mathrm{n} / \mathrm{q}$ & $\mathrm{fr}$ \\
\hline Machaerium nictitans (Vell.) Benth. & bico-de-pato & co & av & 0,3 & $\mathrm{n} / \mathrm{m}$ & cau \\
\hline Sclerolobium denudatum Vogel & ingá-ferro & co & av & 1,2 & $\mathrm{n} / \mathrm{m}$ & cau \\
\hline Stryphnodendron polyphyllum Mart. & canafixa & co & av & 0,2 & $\mathrm{n} / \mathrm{m}$ & $\mathrm{cau}$ \\
\hline LAURACEAE & & & & & & \\
\hline Aniba firmula (Nees et Mart.) Mez & canela-amarela & co & av & 0,2 & $\mathrm{n} / \mathrm{m}$ & $\mathrm{cau}$ \\
\hline Ocotea sp. & canela-preta & co & av & 0,2 & $? / \mathrm{m}$ & $\mathrm{cau}$ \\
\hline Ocotea elegans $\mathrm{Mez}$ & canela & co & av & 0,2 & $\mathrm{n} / \mathrm{m}$ & $\mathrm{cau}$ \\
\hline Persea americana Mill. & abacate & al & av & 1,0 & $\mathrm{e} / \mathrm{q}$ & fr \\
\hline Urbanodendron bahiense (Meisn.) Rohwer & canela-folha-miúda & co & av & 0,2 & $\mathrm{n} / \mathrm{m}$ & $\mathrm{cau}$ \\
\hline LECYTHIDACEAE & & & & & & \\
\hline Cariniana estrellensis (Raddi) Kuntze & jequitibá & co & av & 0,7 & $\mathrm{n} / \mathrm{m}$ & $\mathrm{cau}$ \\
\hline Couratari pyramidata (Vell.) R. Knuth & canudo-de-pito & co & av & 0,2 & $\mathrm{n} / \mathrm{m}$ & $\mathrm{cau}$ \\
\hline Lecythis pisonis Camb. & sapucaia & co & av & 0,3 & $\mathrm{n} / \mathrm{m}$ & cau \\
\hline MELASTOMATACEAE & & & & & & \\
\hline Miconia albicans (Sw.) Triana & chorão & co & $a b$ & 0,2 & $\mathrm{n} / \mathrm{m}$ & cau \\
\hline M. cinnamomifolia (Jacq.) Triana & jacatirão & co & av & 0,3 & $\mathrm{n} / \mathrm{m}$ & cau \\
\hline Tibouchina sp. & tingicuia & co & av & 0,4 & $? / \mathrm{m}$ & cau \\
\hline MELIACEAE & & & & & & \\
\hline Cedrela fissilis Vell. & cedro & co & av & 0,7 & $\mathrm{n} / \mathrm{m}$ & $\begin{array}{c}\text { cau } \\
\text { continu }\end{array}$ \\
\hline
\end{tabular}


Tabela 1 (continuação)

\begin{tabular}{|c|c|c|c|c|c|c|}
\hline Família/Nome científico & Nome popular & Cat & $\mathrm{Hab}$ & VU & O/Loc & Par \\
\hline \multicolumn{7}{|l|}{ MORACEAE } \\
\hline Artocarpus integrifolia Lf. & jaca & al & av & 0,4 & $\mathrm{e} / \mathrm{q}$ & $\mathrm{fr}$ \\
\hline \multicolumn{7}{|l|}{ MUSACEAE } \\
\hline Musa sp. & banana* & al & $a b$ & 1,0 & $\mathrm{e} / \mathrm{q}$ & $\mathrm{fr}$ \\
\hline \multicolumn{7}{|l|}{ MYRISTICACEAE } \\
\hline Virola bicuhyba (Schott) Warb. & bicuíba-folha-larga & co & av & 0,2 & $\mathrm{n} / \mathrm{m}$ & cau \\
\hline V. oleifera (Schott) A.C.Sm. & bicuíba-folha-em-ramo & co & av & 0,2 & $\mathrm{n} / \mathrm{m}$ & cau \\
\hline \multicolumn{7}{|l|}{ MYRSINACEAE } \\
\hline Rapanea ferruginea (Ruiz \& Pav.) Mez & capororoca & co & av & 0,2 & $\mathrm{n} / \mathrm{m}$ & cau \\
\hline \multicolumn{7}{|l|}{ MYRTACEAE } \\
\hline Calyptranthes clusiifolia (Miq.) O. Berg & araçarana-folha-miúda & co & av & 0,3 & $\mathrm{n} / \mathrm{m}$ & cau \\
\hline Eugenia brasiliensis Lam. & grumixama-folha-larga & co & av & 0,2 & $\mathrm{n} / \mathrm{m}$ & cau \\
\hline E. sulcata Spring et Martius & grumixama-folha-miúda & co & av & 0,2 & $\mathrm{n} / \mathrm{q}$ & cau \\
\hline E. uniflora $\mathrm{L}$. & pitanga & $\mathrm{al} / \mathrm{me}$ & av & 0,7 & $\mathrm{n} / \mathrm{q}$ & fr/fo \\
\hline Plinia edulis (Vell.) Sobral & araçarana-folha-larga & co & $a b$ & 0,2 & $\mathrm{n} / \mathrm{m}$ & cau \\
\hline P. glomerata (O. Berg) Amshoff & cambucá & $\mathrm{al} / \mathrm{le}$ & av & 0,4 & $\mathrm{n} / \mathrm{r}$ & $\mathrm{fr}$ \\
\hline P. trunciflora (O. Berg) Kausel & jaboticaba & $\mathrm{al}$ & av & 0,4 & $\mathrm{n} / \mathrm{q}$ & $\mathrm{fr}$ \\
\hline Psidium cattleianum Sabine & araçá & al & $a b$ & 0,4 & $\mathrm{n} / \mathrm{r}$ & $\mathrm{fr}$ \\
\hline P. guajava $\mathrm{L}$. & goiaba & al & $a b$ & 0,3 & $\mathrm{n} / \mathrm{q}$ & $\mathrm{fr}$ \\
\hline Syzygium cumini (L.) Skeels & jamelão & al & av & 0,4 & $\mathrm{e} / \mathrm{q}$ & $\mathrm{fr}$ \\
\hline \multicolumn{7}{|l|}{ POACEAE } \\
\hline Cymbopogon citratus (DC.) Stapf. & capim-limão & me & $\mathrm{hb}$ & 0,7 & $\mathrm{e} / \mathrm{q}$ & fo \\
\hline Imperata brasiliensis Trin. & sapê & co & $\mathrm{hb}$ & 0,1 & $\mathrm{n} / \mathrm{q}$ & fo \\
\hline Merostachys ternata Nees & bambu-taquara & co & $a b$ & 0,7 & $\mathrm{n} / \mathrm{q}$ & cau \\
\hline \multicolumn{7}{|l|}{ RUTACEAE } \\
\hline Citrus aurantium L. & laranja-da-terra & $\mathrm{al} / \mathrm{me}$ & av & 0,9 & $\mathrm{e} / \mathrm{q}$ & fr/fo \\
\hline C. limon (L.) Burm. f. & limão & $\mathrm{al}$ & av & 0,3 & $\mathrm{e} / \mathrm{q}$ & $\mathrm{fr}$ \\
\hline C. sinensis (L.) Osbeck & laranja & $\mathrm{al} / \mathrm{me}$ & av & 0,9 & $\mathrm{e} / \mathrm{q}$ & fr/fo \\
\hline Citrus sp. & lima & al & av & 0,3 & $\mathrm{e} / \mathrm{q}$ & $\mathrm{fr}$ \\
\hline \multicolumn{7}{|l|}{ SAPINDACEAE } \\
\hline Allophylus melanophloeus Radlk. & cubatã-folha-miúda & le & av & 0,4 & $\mathrm{n} / \mathrm{q}$ & cau \\
\hline Cupania furfuracea Radlk. & cubatã-folha-larga & le & av & 0,4 & $\mathrm{n} / \mathrm{q}$ & cau \\
\hline C. vernalis Cambess & arco-de-peneira & co & av & 0,2 & $\mathrm{n} / \mathrm{m}$ & cau \\
\hline \multicolumn{7}{|l|}{ SOLANACEAE } \\
\hline Capsicum baccatum L. & pimenta-comari & al & $\mathrm{hb}$ & 0,6 & $\mathrm{e} / \mathrm{q}$ & $\mathrm{fr}$ \\
\hline C. baccatum $\mathrm{L}$. & pimenta-unha-de-velha & al & $\mathrm{hb}$ & 0,2 & $\mathrm{e} / \mathrm{q}$ & $\mathrm{fr}$ \\
\hline C. chinense Jacq. & pimenta-de-cheiro & al & $\mathrm{hb}$ & 0,6 & $\mathrm{e} / \mathrm{q}$ & $\mathrm{fr}$ \\
\hline \multicolumn{7}{|l|}{ VERBENACEAE } \\
\hline Aloysia gratissima (Gillies \& Hook) Tronc. & novalgina-em-folhas & me & $\mathrm{hb}$ & 0,6 & $\mathrm{e} / \mathrm{q}$ & fo \\
\hline Citharexylum myrianthum Cham. & tarumã & co & av & 0,1 & $\mathrm{n} / \mathrm{m}$ & cau \\
\hline
\end{tabular}

*Espécies visualizadas e documentadas por fotografias (não coletadas).

considerado importante na cultura e tradição da comunidade caiçara de Martim de Sá.

A categoria de uso que teve o segundo maior número de citações foi alimentar, com destaque para abacate (Persea americana), banana (Musa sp.), mandioca (Manihot esculenta) e palmito (Euterpe edulis), mencionados por todos os entrevistados e ambos com valor de uso igual a 1,0. Nessa categoria os recursos mais utilizados são frutos $(85,7 \%)$, palmito $(9,5 \%)$ e uma raiz, a mandioca $(4,7 \%)$. São plantas principalmente cultivadas, sejam elas nativas ou exóticas. A mandioca (Manihot esculenta) foi citada em todas as entrevistas ( $\mathrm{VU}=1,0)$. Três áreas na comunidade são destinadas para seu cultivo, realizado no regime roça de coivara, nome regional dado à prática agrícola constituída de roça e queima. A mandioca é usada principalmente na fabricação de farinha nas chamadas casas de farinha, locais onde se processa o produto com mão de obra de toda unidade familiar. A Fig. 4 expõe a contribuição das categorias de uso na composição do valor de uso para as 10 espécies mais mencionadas nas entrevistas.
$\mathrm{Na}$ categoria medicinal as folhas são os recursos mais utilizados. As plantas de uso medicinal são importantes para os moradores $(0,2 \unlhd U \leq 0,9)$ mesmo que tenham tido destaque menor entre as plantas com maiores valores de uso. Não foram relatados muitos casos de doenças, embora esta questão tenha sido perguntada nas entrevistas. As folhas da pitanga (Eugenia uniflora), da laranja (Citrus sinensis) e da laranja-da-terra (Citrus aurantium) são utilizadas na forma de infusão, separadas ou combinadas, para gripes, resfriados e dores de garganta principalmente para as crianças que são apontadas, na comunidade, como as mais suscetíveis a essas enfermidades. A erva-de-santamaria (Chenopodium ambrosioides) é empregada como vermífugo também, predominantemente, para as crianças. As folhas da novalgina-em-folhas (Aloysia gratissima) são usadas para "qualquer dor no corpo, febre e dor de cabeça".

Apenas três espécies alcançaram elevado valor de uso e a maioria das espécies úteis obteve baixos valores para esse índice. Isto também aconteceu em um estudo com afro-descendentes (Galeano 2000) e com moradores de uma 
Tabela 2. Usos da vegetação pela comunidade caiçara Martim de Sá, Paraty, RJ, Brasil, ordenadas por categoria de uso.

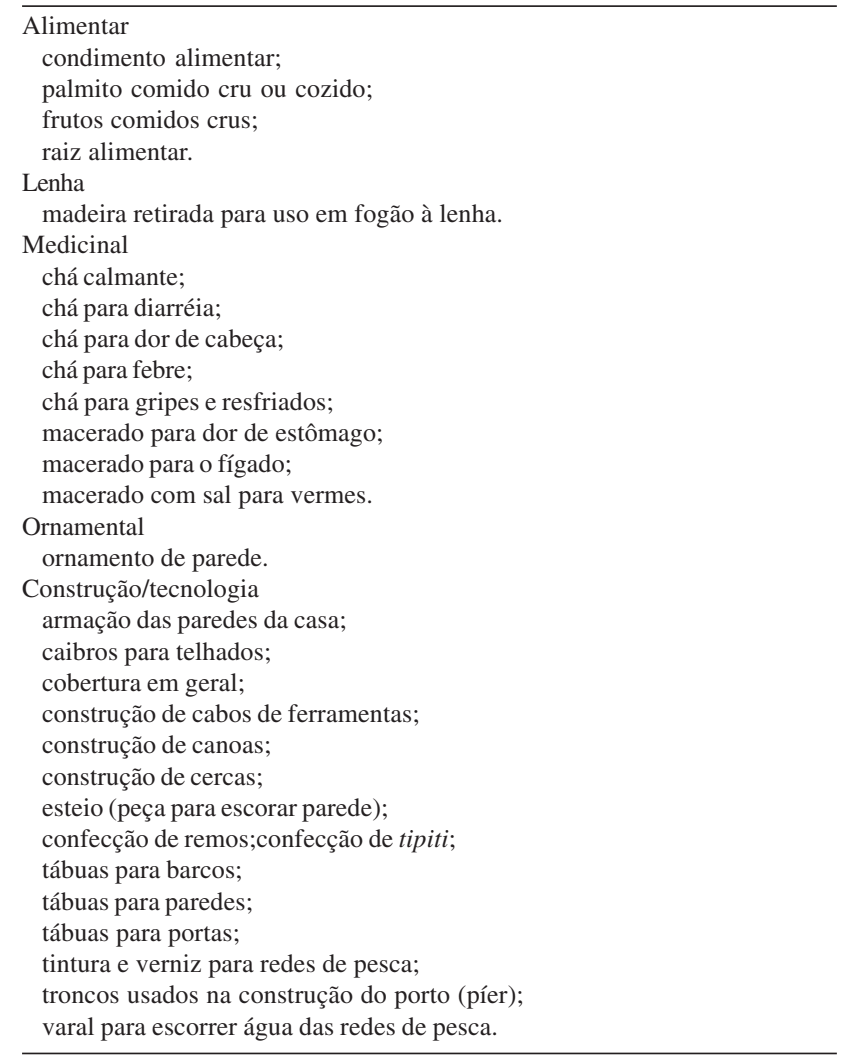

comunidade no semi-árido (Ferraz et al. 2006). Isso demonstra que cada informante possui um conjunto próprio de plantas úteis mostrando que o conhecimento etnobotânico entre os entrevistados é bastante prolixo.

Sete espécies foram citadas para uso como lenha: pimentinha (Erythroxylum vacciniifolium), cambucá (Plinia glomerata), aroeira (Schinus terebinthifolia), cubatã-folhamiúda (Allophyllus melanophloeus), cubatã-folha-larga (Cupania furfuracea), casca-preta (Pera glabrata) e milhocozido (Licania hoehnei). Das espécies mencionadas nas entrevistas 41 estão na categoria construção/tecnologia (48,2\% das espécies citadas), seguida por 24 na categoria alimentar $(28,3 \%), 11$ na categoria medicinal $(12,9 \%)$, sete

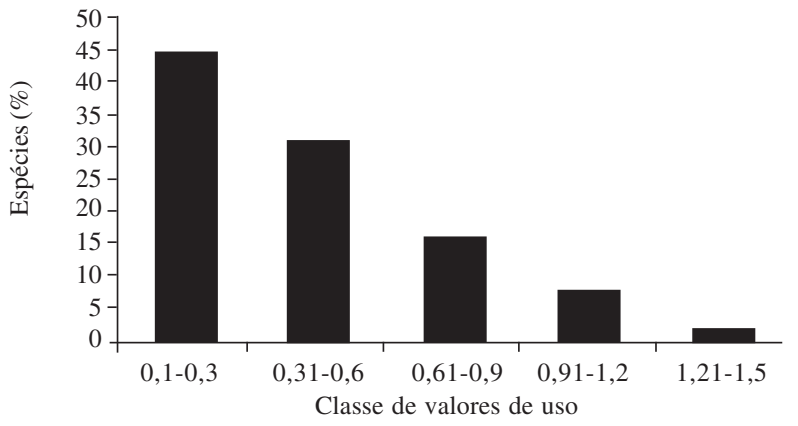

Figura 3. Distribuição do número de espécies citadas por classe de valor de uso na comunidade caiçara de Martim de Sá, Paraty, RJ, Brasil.

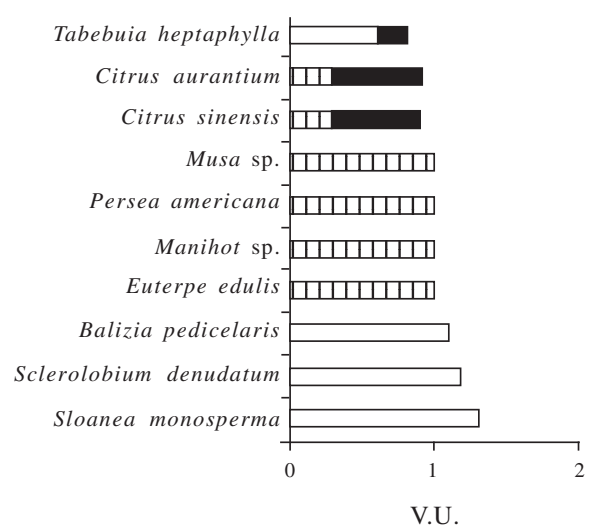

Figura 4. Contribuição das categorias de uso na composição do valor de uso para as 10 espécies mais mencionadas nas entrevistas realizadas na comunidade caiçara de Martim de Sá, Paraty, RJ, Brasil ( $\square$ = construção/tecnologia; $\square=$ alimentar; $\square=$ medicinal; $\square=$ lenha; $\mathbb{Z}=$ ornamental).

na categoria lenha $(8,3 \%)$ e duas na categoria ornamental $(2,3 \%)$. Os artefatos apontados nas entrevistas pelos caiçaras foram o tipiti, cestos para transporte de alimentos, remos de canoas e colheres de pau.

Homens e mulheres têm conhecimentos diferentes sobre as plantas, principalmente com relação às utilizadas para construção/tecnologia, que são do domínio masculino e as para alimentação, medicinais e lenha, que são de domínio feminino (Fig. 5). Informantes jovens e idosos também mostraram diferenças no conhecimento sobre as plantas úteis, embora um casal de informantes jovens tenha se destacado com conhecimento em todas as categorias. Tal fato pode ser justificado pela convivência direta que o casal jovem tem com o casal mais idoso e com maior conhecimento.

Hanazaki et al. (2000) afirmam que os homens tendem a conhecer mais plantas nativas utilizadas para construções/ tecnologias e as mulheres a ter um conhecimento maior sobre plantas medicinais em termos da quantidade e da multiplicidade de citações. A pesquisa realizada na comunidade Martim de Sá corrobora com essas informações.

Índice de diversidade - O índice de Shannon-Wiener $\left(\mathrm{H}^{\prime}\right)$ obtido foi de 1.81 (base 10) mostrando que os moradores ainda possuem um conhecimento diverso acerca dos

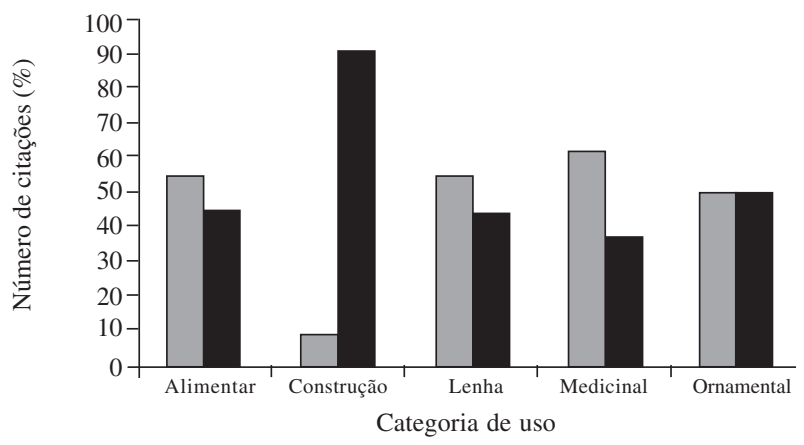

Figura 5. Número de citações de homens e mulheres por categoria de uso para a comunidade caiçara de Martim de Sá, Paraty, RJ, Brasil ( 1 = mulheres; - = homens). 
recursos da biodiversidade. Alguns estudos de etnobotânica realizados nos últimos dez anos no litoral sudeste do Brasil vêm demonstrando que comunidades locais detêm um conhecimento que deve ser estudado e valorizado. A Tab. 3 mostra uma compilação de informações obtidas em alguns desses estudos com destaque para o índice de diversidade de Shannon-Wiener.

O estudo de Figueiredo et al. (1997) compara o conhecimento sobre a diversidade do uso de plantas medicinais da comunidade de Calhaus (Ilha de Jaguanum) localizada na Baía de Sepetiba, RJ com as comunidades de Gamboa (também localizada na Baía de Sepetiba e da Ilha de Búzios). Encontraram resultados semelhantes entre os índices de diversidade para essas comunidades e concluíram que comunidades que vivem em pequenas ilhas e em ilhas distantes da costa usam pequena quantidade de plantas.

O estudo de Rossato et al. (1999) apresenta informações sobre o uso de plantas em cinco comunidades caiçaras no litoral norte de São Paulo. Usaram índices de diversidade para comparar as comunidades. Encontraram uma alta diversidade de plantas usadas na costa da Mata Atlântica: 276 plantas usadas para alimentação, medicina e construção. De acordo com os autores os caiçaras dependem da medicina tradicional e plantas medicinais foram especialmente citadas nas entrevistas. Apontaram uma diversidade menor de plantas medicinais citadas nas ilhas quando comparadas às comunidades continentais.

O trabalho de Hanazaki et al. (2000) mostra informações sobre o uso de plantas em duas comunidades caiçaras da mata atlântica localizadas no litoral de São Paulo - Ponta do Almada e praia de Camburí. Os autores utilizaram índices de diversidade para comparar os usos de plantas entre as comunidades e entre idade e gênero de cada comunidade. Encontraram diferenças quantitativas no conhecimento sobre plantas entre os gêneros para cada uso (medicinal, alimentação e artesanato). Informantes idosos e jovens também mostraram diferenças no conhecimento sobre plantas para artesanato e medicinal, mas não para plantas comestíveis. Obtiveram dados referentes a 227 etnoespécies em 102 entrevistas realizadas. Das espécies identificadas, 30 são comuns ao presente estudo.

Fonseca-Kruel \& Peixoto (2004) apresentam informações sobre o uso de plantas de restinga em uma comunidade de pescadores artesanais localizada em Arraial do Cabo, RJ.
Obtiveram 444 citações de uso das 68 espécies, distribuídas entre 61 gêneros e 42 famílias. Empregaram o índice de Shannon para análise da diversidade de espécies e concluíram que os pescadores possuem bom conhecimento da biodiversidade local quando comparado a outros estudos da costa brasileira.

O índice de Shannon obtido para a comunidade Martim de Sá mostra um valor intermediário quando comparado com os de outros estudos. Os trabalhos de Rossato et al. (1999), realizado com cinco comunidades caiçaras e o de Hanazaki et al. (2000), realizado com duas comunidades caiçaras apresentam valores mais altos. Figueredo et al. (1997) e Fonseca-Kruel \& Peixoto (2004) enfocaram uma só comunidade e encontraram valores mais baixos do índice e muito próximo do obtido neste trabalho. Observando o número de citações fornecido por cada estudo, vemos que uma coerência entre o número de citações de plantas úteis feitas pelas comunidades caiçaras do litoral sudeste do Brasil analisadas, excetuando-se o estudo de Rossato et al. 1999 que entrevistaram um número elevado de informantes.

Os caiçaras da comunidade de Martim de Sá possuem um amplo conhecimento da diversidade de plantas do local onde vivem. As entrevistas mostraram que $74 \%$ dos recursos utilizados por eles são nativos do bioma Mata Atlântica. Isto pode estar relacionado à localização da comunidade em região de alta diversidade biológica e ao isolamento do principal centro urbano da região, a cidade de Paraty, RJ. Todos os moradores incorporam a identidade de caiçaras. Mantém técnicas e práticas de produção e processamento de mandioca, cultivo e coleta de frutos e fabricação de utensílios e canoas para a pesca.

Em feriados prolongados têm trabalhado no atendimento aos turistas que procuram o lugar para acampar, e estão obtendo algum ganho econômico com isso. Aparentemente estão conseguindo aliar as atividades tradicionais à nova atividade. Embora haja um forte sentimento verbalizado de diferentes maneiras sobre a importância de conservar o ambiente onde vivem, o compromisso de governo com as UC não parece compreendido por eles.

Durante os trabalhos de campo observou-se grande fluxo de turistas no local e algumas adaptações que os caiçaras fizeram em uma das casas visando atendê-los melhor. $\mathrm{O}$ aumento do fluxo turístico sem planejamento aliado a ausência de fiscalização dos órgãos ambientais responsáveis pela UC pode comprometer o modo de vida do caiçara da

Tabela 3. Comparação de informações compiladas de estudos realizados em ecossistemas costeiros brasileiros indicando fonte, local de realização do estudo, Veg = tipo de vegetação, Abr = abrangência do estudo (número de categorias de uso), N. Inf. = número de informantes, N. esp = número de espécies citadas, N. cit = número de citações, $H^{\prime}$ - Índice de Shannon-Wiener (B.10 - base 10). (R - restinga; Ma - mata atlântica; C - áreas cultivadas ou roças; (-) indica ausência de informação).

\begin{tabular}{|c|c|c|c|c|c|c|c|}
\hline Fonte & Local & Veg & Abr & N. inf & N. esp & N. cit & $H^{\prime}$ B. 10 \\
\hline Figueiredo et al. 1997 & Praia Calhaus (Ilha de Jaguanum), RJ & $\mathrm{Ma}$ & 3 & 42 & 75 & 482 & 1.53 \\
\hline Rossato et al. 1999 & SP & Ma & - & 162 & 277 & 3.109 & 2.06 \\
\hline Hanazaki et al. 2000 & Ponta do Almada, SP & $\mathrm{Ma}$ & 3 & - & 227 & - & 1.99 \\
\hline Fonseca-Kruel \& Peixoto 2004 & Arraial do Cabo, RJ & $\mathrm{R}$ & 6 & 15 & 68 & 444 & 1.78 \\
\hline Este trabalho & Paraty, RJ & $\mathrm{Ma}, \mathrm{R}$ & 5 & 10 & 73 & 355 & 1.81 \\
\hline
\end{tabular}


RE da Juatinga. Esta área protegida ainda não tem plano de manejo instituído e questões como limitação do número de turistas que freqüentam o local e mesmo a segurança dos moradores fica fragilizada.

Nesse sentido é de extrema importância que se decida rapidamente, com a participação das comunidades caiçaras, a categoria de UC mais adequada para o local. Acredita-se que a categoria de manejo Reserva de Desenvolvimento Sustentável seja a mais apropriada, pois permite a presença de "comunidades tradicionais cuja existência baseia-se em sistemas sustentáveis de exploração de recursos naturais, desenvolvidos ao longo de gerações e adaptados às condições ecológicas locais e que desempenham um papel fundamental na proteção da natureza e na manutenção da diversidade biológica", sendo permitida a visitação pública, desde que compatível com os interesses locais e de acordo com o disposto no plano de manejo da área (SNUC 2000).

A partir da regulamentação de tal UC e do desenvolvimento dos programas e subprogramas apontados no plano de manejo, atividades de pesca, extrativismo de baixo impacto e turismo visando à conservação e a subsistência da Mata Atlântica e da cultura caiçara podem ser instituídas, de modo a evitar a urbanização do local, estimulando o desenvolvimento regional integrado. É importante que o saber dos moradores seja incorporado na elaboração do plano de manejo, nas estratégias de conservação da biodiversidade in situ da UC e da cultura tradicional caiçara, mas é importante também que os moradores se apropriem do conhecimento sobre a UC na qual vivem e ajudam a preservar.

\section{Agradecimentos}

Aos caiçaras da comunidade Martim de Sá que gentilmente se dispuseram a compartilhar seus conhecimentos e participar desta pesquisa; ao Dr. Ney Pinto França, diretor da APA de Cairuçu IBAMA, pela acolhida da pesquisa; à Escola Nacional de Botânica Tropical do JBRJ pela oportunidade de realização da pesquisa e pelo apoio no período dos trabalhos de campo; aos pesquisadores e estudantes do Jardim Botânico do Rio de Janeiro pelo auxílio na identificação do material botânico: Adriana Q. Lobão, Alexandre Quinet, Ângela S. da F. Vaz, Bruno C. Kurtz, Cyl Farney C. de Sá, Elsie F. Guimarães, Inês Machline Silva, José F. Baumgratz, Luciana F. G. Silva, Marcelo da C. Souza e Ronaldo Marquete; a Artur C. Amaral, pelo auxílio na confecção das Figuras 1 e 2 e a Maria Otávia S. Crepaldi, pela leitura crítica do texto.

\section{Referências bibliográficas}

Adams, C. 2000. Caiçaras na Mata Atlântica: pesquisa científica versus planejamento e gestão ambiental. São Paulo, Annablume.

Albuquerque, U.P. \& Lucena, R.F.P. (orgs.) 2004. Métodos e técnicas na pesquisa etnobotânica. Recife, NUPEEA.

Alexiades, M. 1996. Collecting Ethnobotanical Data: An introduction to basic concepts and techniques. Pp. 53-94. In: Selected Guidelines for Ethnobotanical Research: A field manual. The New York Botanical Garden.

APG II (Angiosperm Phylogenetic Group). 2003. An update of the Angiosperm Phylogenetic Group classification for the orders and families of flowering plants. Botanical Journal of the Linnean Society 141: 399-436.
Begossi, A. 1996. Use of ecological methods in ethnobotany: diversity indices. Economic Botany 50: 280-289.

Berkes, F.; Kislalioglu, M.; Folke, C. \& Gadgil, M. 1998. Exploring the basic ecological unit: ecosystem-like concepts in tradicional societies. Ecosystems 1: 404-415.

Bernard, H.R. 1995. Research Methods in Antropology. Qualitative and Quantitative Approachs. $2^{\text {nd }}$ ed. Altamira Press, Walnut Creek.

Brummitt, R.K. \& Powel, C.E. 1992. Authors of plants names. Kew, Royal Botanic Gardens.

Camargo, M.T.A. 2003. Etnofarmacobotânica - Conceituação e Metodologia de Pesquisa. São Paulo, Humanitas/FFLCH/ USP: Terceira Margem.

Cavalieri, L. 2003. A comunidade caiçara no processo de reclassificação da Reserva Ecológica da Juatinga. Dissertação (Mestrado em Geografia Humana). Faculdade de Filosofia, Letras e Ciências Humanas - Universidade de São Paulo.

Companhia de Pesquisa de Recursos Minerais - CPRM. 1983. Projeto Carta Geológica do Estado do Rio de Janeiro. Folhas: Mangaratiba, Ilha Grande, Cunhambebe, Angra dos Reis, Rio Mambucaba/Campos de Cunha, Parati, Cunha, Picinguaba e Juatinga. Rio de Janeiro, DRM-RJ/CPRM, relatório final. 3v.

Cunningham, A.B. 2000. Applied Ethnobotany - People, Wild Plants Use and Resourse Management. London, Earthscan.

Decreto Estadual $N^{\circ} 17.981$ de 30 de outubro de 1992. Cria a Reserva Ecológica de Juatinga, no Município de Parati, e dá outras providências. Rio de Janeiro, RJ. 1p. Disponível em: http:// www.ief.rj.gov.br/legislacao/docs/17981.doc (Acesso em: 29/02/2008).

Decreto Federal $N^{\circ} 89.242$, de 27 de dezembro de 1983. Dispõe sobre a criação da Área de Proteção Ambiental de Cairuçu, no Estado do Rio de Janeiro e dá outras providências. Brasília, DF. $2^{\circ}$. Disponível em: http://www.ibama.gov.br/siucweb/ mostraDocLegal.php?seq_uc $=36 \&$ seq_tp_documento $=3 \&$ seq_finaliddoc $=7$ (Acesso em: 29/02/2008).

Diegues, A.C.S. \& Arruda, R.S.V. 2001. Saberes tradicionais e biodiversidade no Brasil. Brasília: Ministério do Meio Ambiente; São Paulo, USP. (Biodiversidade 4).

Diegues, A.C.S. 2003. Aspectos sociais e culturais do uso de recursos florestais da Mata Atlântica. In: Simões, L.L. \& Lino, C.F. Sustentável Mata Atlântica: a exploração de seus recursos florestais. $2^{\mathrm{a}}$ ed. atual. São Paulo, Editora Senac.

Ferraz, J.S.F.; Albuquerque, U.P. \& Meunier, I.M.J. 2006. Valor de uso e estrutura da vegetação lenhosa às margens do riacho do Navio, Floresta, PE, Brasil. Acta Botanica Brasilica 20: 125-134.

Figueiredo, G.M.; Leitão Filho, H.F. \& Begossi, A. 1997. Ethnobotany os Atlantic Forest Coastal Communities: II. Diversity of Plant Uses at Sepetiba Bay (SE Brazil). Human Ecology 25: 353-360.

Fonseca-Kruel, V.S. \& Peixoto, A.L. 2004. Etnobotânica na Reserva Extrativista Marinha de Arraial do Cabo, RJ, Brasil. Acta Botanica Brasilica 18: 177-190.

Fundação Instituto de Desenvolvimento Econômico e Social do Rio de Janeiro (FIDERJ). 1978. Indicadores climatológicos: a distribuição espacial dos tipos climáticos Thornthwaite.

Galeano, G. 2000. Forest use at the Pacific Coast of Chocó, Colômbia: a quantitative approach. Economic Botany 54: 358-376.

Garrote, V. 2004. Os quintais caiçaras, suas características sócioambientais e as perspectivas para a comunidade do Saco do Mamanguá, Paraty - RJ. Dissertação (Mestrado em Recursos Florestais). ESALQ/USP.

Hanazaki, N.; Tamashiro, J.Y.; Leitão Filho, H.F. \& Begossi, A. 2000. Diversity of plant uses in two Caiçara communities from the Atlantic Forest coast, Brazil. Biodiversity and Conservation 9: 597-615. 
Hanazaki, N. 2002. Conhecimento caiçara para o manejo de recursos naturais. In: U.P. Albuquerque et al. (orgs.). Atualidades em Etnobiologia e Etnoecologia. Recife, SBEE.

Instituto Estadual de Florestas (IEF/RJ). 2006. Portal do Instituto Estadual de Florestas do Estado do Rio de Janeiro. Disponível em: <http://www.ief.rj.gov.br/> (Acesso em: 10/10/2006).

Lima, H.C., Peixoto, A.L. \& Pereira, T.S. 2002. Conservação da Mata Atlântica. In: L. Sylvestre \& M.M. Rosa. Manual Metodológico para Estudos Botânicos na Mata Atlântica. UFRRJ. Seropédica.

Magurran, A.E. 1988. Ecological diversity and its measurement. New Jersey, Princeton University Press, Princeton.

Marques, M.C.M. (org.) 1997. Mapeamento da cobertura vegetal e listagem das espécies ocorrentes na Área de Proteção Ambiental de Cairuçu, Município de Parati, RJ. Série Estudos e Contribuições $\mathbf{n}^{\circ}$ 13. Rio de Janeiro, Instituto de Pesquisas Jardim Botânico do Rio de Janeiro.

Marques, M.C.M.; Vaz, A.S.F. \& Marquete, R. (orgs.). 1997. Flórula da APA de Cairuçu, Parati, RJ: Espécies Vasculares. Série Estudos e Contribuições $\mathbf{n}^{\mathbf{0}} \mathbf{1 4}$. Rio de Janeiro, Instituto de Pesquisas Jardim Botânico do Rio de Janeiro.

Mori, S.A.; Silva, L.A.M. \& Coradin, L. 1989. Manual de manejo do herbário fanerogâmico. $2^{a}$ ed. Ilheus, Ceplac.

Myers, N.; Mittermeier, R.A.; Mittermeier, C.G.; Fonseca, G.A.B. \& Kent, J. 2000. Biodiversity hotspots for conservation priorities. Nature 403: 853-858.
Phillips, O. \& Gentry, A.H. 1993a. The useful plants of Tambopata, Peru: I. Statistical Hypoteses tests with a new quantitative technique. Economic Botany 47: 15-32.

Phillips, O. \& Gentry, A.H. 1993b. The Useful Plants of Tambopata, Peru: II. Additional, Hypothesis Testing in Quantitative Ethnobotany. Economic Botany 47: 33-43.

Prance, G.T. 1991. What is ethnobotany today? Text presented at the First international Congress on Ethnopharmacology, Strasbourg (5-9 June, 1990). Elsevier Scientific Publishers Ireland Ltd.

Prance, G.T. 1995. Ethnobotany today and in the future. Pp. 6068. In: R.E. Shultes \& V. Reis. Ethnobotany: evolution of a discipline.

Rossato, S.C.; Leitão Filho, H. \& Begossi, A. 1999. Ethnobotany of Caiçaras of the Atlantic Forest Coast (Brasil). Economic Botany 53: $387-395$.

Sinay, L. 2002. Ecoturismo e Culturas Tradicionais - Estudo de Caso: Martim de Sá. Dissertação (Mestrado em Psicossociologia de Comunidades e Ecologia Social). EICOS/CFCH - UFRJ.

Sistema Nacional de Unidades de Conservação da Natureza - SNUC: Lei Federal $\mathrm{N}^{\circ}$ 9.985, de 18 de julho de 2000; Decreto Federal $\mathrm{N}^{\circ}$. 4.340, de 22 de agosto de 2002. $5^{\text {a }}$ ed. aum. Brasília, MMA/SBF. 2004. 56 p.

Veloso, H.P.; Rangel Filho, A.L.R. \& Lima, J.C.A. 1991. Classificação da Vegetação Brasileira adaptada a um Sistema Universal. IBGE/CDDI. Dep. de Documentação e Biblioteca. 